\title{
Testing for variants in CYP2C19: population frequencies and testing experience in a clinical laboratory
}

\author{
Charles M. Strom, MD, PhD'1, Dana Goos, BS'1, Beryl Crossley, MD'1, Ke Zhang, PhD'1, Arlene \\ Buller-Burkle, PhD', Michael Jarvis, PhD'1, Franklin Quan, PhD', Mei Peng, PhD' and Weimin Sun, PhD'
}

Purpose: We sought to determine the genotype frequencies for cytochrome p450 enzyme 2C19 variant alleles both in the US panethnic population and various US ethnic groups and to establish the frequency of clinically actionable genotypes.

Methods: Analytical results were obtained from 1,396 consecutive samples submitted for cytochrome p450 enzyme 2C19 genotyping tests and stored in a proprietary database. This database was queried and genotypes and predicted phenotypes established. Anonymized samples were obtained from specimens submitted for cystic fibrosis genotyping that contained ethnicity information. Samples from 357, 149, and 346 individuals self-identified as white, African American, and Hispanic, respectively, were analyzed. In addition, 342 anonymized samples submitted for Ashkenazi Jewish panel testing were analyzed.
Results: Significant ethnic differences were observed in the frequencies of the ${ }^{\star} 17$ ultrarapid allele among the various groups studied. In the pan-ethnic population, $3.8 \%$ of tested patients were classified as ultrarapid metabolizers, $24 \%$ as extensive metabolizers heterozygous for ${ }^{\star}{ }^{*} 17$ ultrarapid allele, $27 \%$ as intermediate metabolizers, and $3.5 \%$ as poor metabolizers. Using stringent criteria, $7.3 \%$ of individuals would have clinically actionable genotypes. In addition, we detected two individuals with a haplotype of ${ }^{*} 2 /{ }^{\star} 17$ and a single individual with a haplotype of ${ }^{\star} 4 /{ }^{\star} 17$ indicating that the ${ }^{\star} 17$ hypermetabolic allele can occur on $\mathrm{a}^{\star} 1,{ }^{\star} 2$, or ${ }^{\star} 4$ background.

Genet Med 2012:14(1):95-100

Key Words: clopidogrel; cytochrome p450 2C19; pharmacogenomics

\section{INTRODUCTION}

The cytochrome p450 enzyme 2C19 (CYP2C19) is responsible for metabolizing a large number of commonly prescribed medications such as omeperizol, clopidogrel, phenytoin, imipramine, indomethacin, and warfarin. ${ }^{1}$ Clopidogrel is a prodrug that is converted to its active form by CYP2C19. The enzyme has several common loss of function alleles and a single gain of function allele. Several articles have reported an increase in adverse outcomes in both poor and intermediary metabolizers treated with standard doses of clopidogrel. ${ }^{2-17}$ Two large meta-analyses have confirmed these findings. ${ }^{18,19}$

A promoter variant ${ }^{*} 17$ causes increased CYP2C19 activity and is classified as an ultrarapid metabolizer allele. ${ }^{20} \mathrm{~A}$ study has demonstrated an increase in hemorrhagic complications in patients who carry the ultrarapid metabolizer allele ${ }^{\star} 17 .{ }^{20}$ Subsequently, several studies including a large meta-analysis have confirmed that the ${ }^{\star} 17$ allele is a gain-of-function allele associated with increased activity of clopidogrel and increased risk of hemorrhagic events for patients treated with standard doses of clopidogrel. ${ }^{21-27}$ Estradiol is also metabolized by CYP2C19. In a case-control study of 1,015 patients with breast cancer, women who were taking hormone replacement therapy for more than 10 years and carried a ${ }^{\star} 17$ CYP2C19 allele had a decreased risk of breast cancer (odds ratio $=0.57) .{ }^{28}$ Women not taking hormones had a more modest reduction (odds ratio $=0.77 \%){ }^{28}$
Although a few studies have failed to replicate the association of CYP2C19 loss of function alleles with adverse outcomes while on clopidogrel therapy, ${ }^{29}$ two large meta-analyses have confirmed the association. ${ }^{18,19}$ The Food and Drug Administration (FDA) added a "box warning" to clopidogrel recommending that genetic testing for CYP2C19 variants be considered when placing a patient on clopidogrel therapy. ${ }^{30}$ The warning states, "Based on literature data, patients with genetically reduced CYP2C19 function have lower systemic exposure to the active metabolite of clopidogrel and diminished antiplatelet responses, and generally exhibit higher cardiovascular event rates following myocardial infarction than do patients with normal CYP2C19 function." ${ }^{30}$ The warning specifically cites individuals with poor metabolizer status as being at risk for poor outcomes.

A detailed discussion of the data leading to these recommendations is beyond the scope of this article. An excellent review can be found authored by the American College of Cardiology Foundation Task Force of Clinical Expert Consensus documents and the American Heart Association. ${ }^{31}$

There is, as yet, no evidence-based consensus on appropriate clinical interventions for various CYP2C19 genotypes. Some have suggested alternative medications could be used for poor metabolizers ${ }^{32}$ and dosage reduced for carriers and homozygotes for ultrarapid alleles. A multicenter trial with 
411 patients determined that increasing the clopidogrel dose in CYP2C19 intermediate metabolizers overcame their resistance to clopidogrel when measured by platelet reactivity monitoring. ${ }^{33}$ However, a pilot study showed no correlation between platelet reactivity testing and CYP2C19 genotyping for patients on clopidogrel therapy. However, this study had only 41 patients. ${ }^{34}$ We must await large-scale clinical trials to fully answer whether platelet reactivity testing, CYP2C19 genotyping, or a combination of both will be the best guide to clopidogrel dosing.

Several studies have examined the frequency of various CYP2C19 alleles worldwide. These include Brazil, ${ }^{35}$ Iran, ${ }^{36,37}$ East Asia, ${ }^{38}$ Ghana, ${ }^{39}$ United States Ashkenazi Jews, ${ }^{40}$ Greece, ${ }^{41}$
Mexican Americans, ${ }^{42}$ Bolivia, ${ }^{43}$ Israel, ${ }^{44}$ Malaysia, ${ }^{45}$ Egypt,${ }^{46}$ and whites of European descent. ${ }^{47}$ However, these studies were limited to a small number of deficiency alleles and did not include the ${ }^{\star} 17$ gain-of-function allele.

It is important for geneticists to be aware of this FDA recommended use of genotype testing and the expected frequencies of clinically actionable genotypes. In this study, we genotyped 852 consecutive unselected anonymized patient samples submitted for cystic fibrosis genotyping who had provided their ethnicity and 342 samples submitted for Ashkenazi Jewish panel testing. We then tabulated the results of 1,396 consecutive genotypes submitted for CYP2C19 testing to our clinical laboratory.

Table 1 CYP2C19 genotype, phenotype, and allele frequencies for various ethnicities

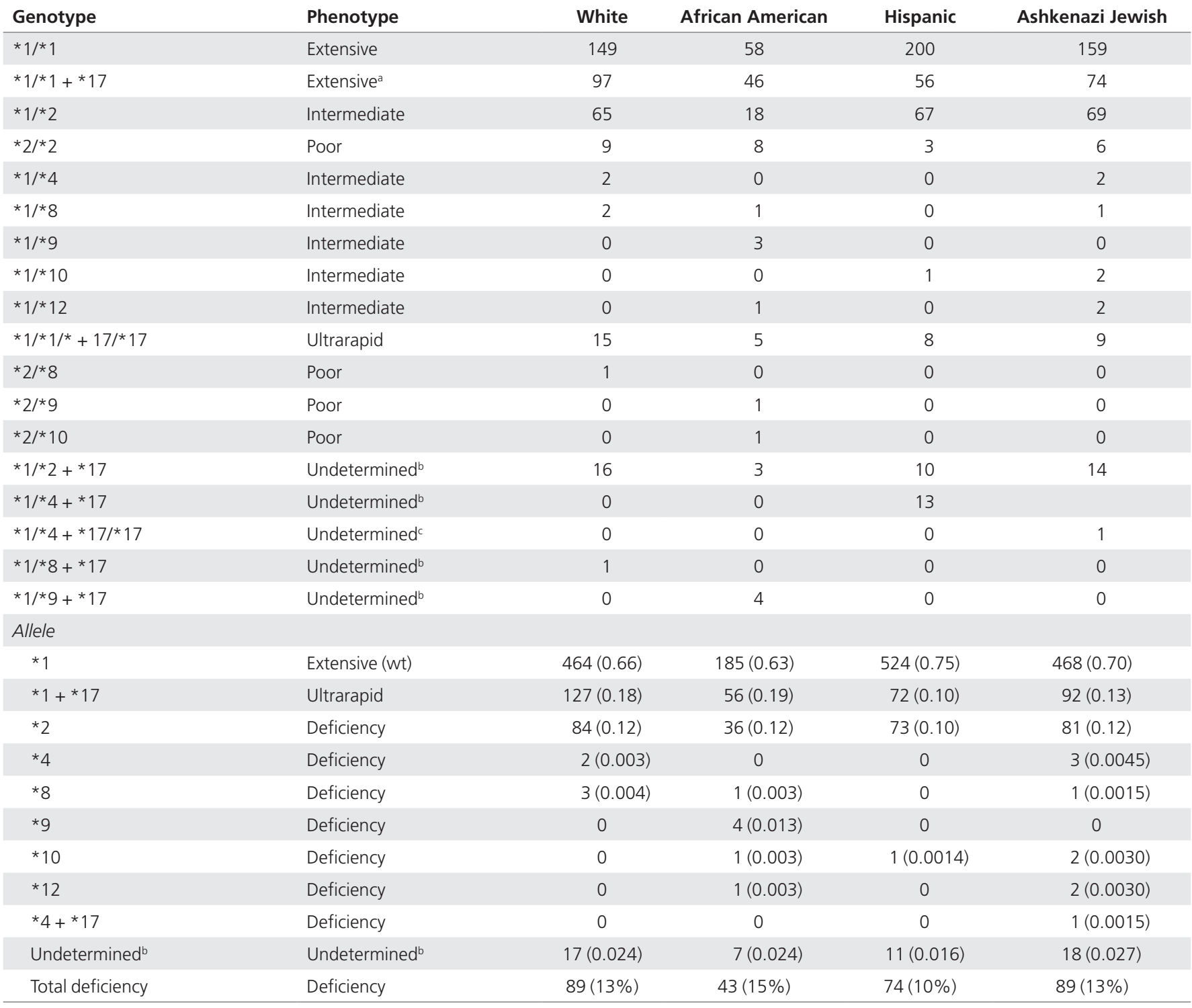

${ }^{a} * 1 / * 17$ are classified as extensive metabolizers but are at higher risk for hemorrhagic complications while on standard doses of clopidogrel. ${ }^{b} \mathrm{As}$ these patients are double heterozygotes for the * 17 allele and a deficiency allele, it is impossible to determine the haplotype without performing family studies. ${ }^{\top}$ This individual has one allele that contains the $* 1+* 17$ and therefore an ultrarapid allele and one allele that is $* 4+* 17$ and therefore a deficiency allele. It is not possible to predict the eventual phenotype from the genotype data. 
Table 2 Predicted phenotype for various ethnic groups

\begin{tabular}{|c|c|c|c|c|}
\hline $\begin{array}{l}\text { Predicted } \\
\text { phenotype }\end{array}$ & $\begin{array}{c}\text { White } \\
(n=357)\end{array}$ & $\begin{array}{l}\text { African } \\
\text { American } \\
(n=149)\end{array}$ & $\begin{array}{l}\text { Hispanic } \\
(n=346)\end{array}$ & $\begin{array}{c}\text { Ashkenazi } \\
\text { Jewish } \\
(n=342)\end{array}$ \\
\hline $\begin{array}{l}\text { Extensive } \\
\text { metabolizer } \\
\left({ }^{*} 1 /{ }^{*} 1\right)\end{array}$ & $149(42 \%)$ & 58 (39\%) & 200 (58\%) & $159(46 \%)$ \\
\hline $\begin{array}{l}\text { Extensive } \\
\text { metabolizer } \\
\left({ }^{*} 1 /{ }^{*} 17\right)\end{array}$ & 97 (27\%) & $46(30 \%)$ & $56(16 \%)$ & $74(22 \%)$ \\
\hline $\begin{array}{l}\text { Ultrarapid } \\
\text { metabolizer } \\
\star 1 / * 17 / * 17\end{array}$ & 15 (4.2\%) & $5(3.3 \%)$ & $8(2.3 \%)$ & $9(2.6 \%)$ \\
\hline $\begin{array}{l}\text { Intermediate } \\
\text { metabolizer } \\
\star 1 /(* 2-10, * 12)\end{array}$ & $69(19 \%)$ & $23(15 \%)$ & $68(20 \%)$ & $76(22 \%)$ \\
\hline $\begin{array}{l}\text { Poor } \\
\text { metabolizer } \\
\left({ }^{*} 2-10, * 12\right) / \\
\left({ }^{*} 2-10, * 12\right)\end{array}$ & $10(2.8 \%)$ & $10(6.7 \%)$ & $3(0.87 \%)$ & $6(1.8 \%)$ \\
\hline $\begin{array}{l}\text { Indeterminant } \\
\text { metabolizer } \\
\text { (see text) }\end{array}$ & $17(4.8 \%)$ & $7(4.7 \%)$ & $11(3.2 \%)$ & $18(5.3 \%)$ \\
\hline
\end{tabular}

\section{Patient samples}

\section{MATERIALS AND METHODS}

We request ethnicity information for all patients submitting samples for cystic fibrosis testing. We receive this information approximately $60 \%$ of the time. Samples of isolated DNA from patients who have supplied ethnicity are anonymized and frozen for future ethnic distribution studies. All identifying information is stripped other than the ethnicity of the sample. Similarly, samples submitted for Ashkenazi Jewish panel testing are stripped of identifiers and stored for future analysis. This procedure has been approved by the Western Institutional Review Board.

All genotyping data from our clinical CYP2C19 assay are stored contemporaneously in a proprietary database. This database does not contain ethnicity information. As we do not provide residual risks for patients, ethnicity is not required for clinical testing. This database was queried for genotyping results.

\section{Sample preparation}

Genomic DNA was prepared from peripheral blood specimens on a 9604 BioRobot or a M96 BioRobot (Qiagen, Valencia, CA) according to manufacturer's instructions. The average concentration of an extracted DNA sample is $15-50 \mathrm{ng} / \mu \mathrm{L}$.

\section{CYP2C19 assay}

Until recently, our CYP2C19 assay analyzed the deficiency alleles ${ }^{\star} 1{ }^{\star} 4$ and the ultrarapid metabolizer allele ${ }^{\star} 17$. We have developed an expanded panel assay that detects the ${ }^{\star} 1-{ }^{\star} 10$, ${ }^{\star} 12$, and ${ }^{\star} 17$ alleles. This expanded panel was used to analyze the ethnic groups.

\section{Multiplex single-nucleotide primer extension reaction}

Six gene regions containing the CYP2C19 variants, which include fragments from the promoter, exons 3-5, and exon 9, were amplified from patient genomic DNA samples in a single multiplex polymerase chain reaction reaction. Extension primers to detect CYP2C19*2 through $\mathrm{CYP} 2 \mathrm{C} 19^{\star} 10$, $\mathrm{CYP} 2 \mathrm{C} 19^{\star} 12$, and $\mathrm{CYP} 2 \mathrm{C} 19^{\star} 17$ were included in the multiplex single-nucleotide primer extension reaction.

\section{Statistical analysis}

Statistical analysis was performed using the Fisher exact test.

\section{RESULTS}

Table 1 represents the ethnic-specific genotyping data for 357 white, 149 African American, 346 Hispanic, and 342 Ashkenazi Jewish patients. Ethnic differences are clearly apparent with whites (18\%) and African Americans (19\%) having nearly twice the rate of the ${ }^{\star} 17$ ultrarapid allele than either Hispanics or Ashkenazi Jews. However, statistical significance was reached only for Hispanic versus white $(P=0.00043)$ and Hispanic versus African American $(P=0.0022)$. All four races had similar allele frequencies for ${ }^{\star} 2$, the most common deficiency allele, and no statistically significant differences were observed. Hardy-Weinberg equilibrium was observed for ${ }^{\star} 2$ and ${ }^{\star} 17$ in all races. There were insufficient numbers of other alleles for analysis. Our observation for the allele frequencies of ${ }^{\star} 1,{ }^{\star} 2,{ }^{\star} 3$, and ${ }^{\star} 15$ in US Ashkenazi Jews was similar to that reported previously. ${ }^{40}$

\section{Predicted phenotypes}

The nomenclature for pharmacogenetics can be confusing and CYP2C19 is no exception. The accepted predicted phenotypes for CYP2C19 define homozygous normal $\left({ }^{\star} 1 /{ }^{\star} 1\right)$ individuals as extensive metabolizers, heterozygous individuals for $\mathrm{a}^{\star} 1$ and deficiency allele as intermediate metabolizers, and homozygotes for a deficiency allele as poor metabolizers. The nomenclature is not yet standardized for carriers of the ${ }^{\star} 17$ ultrarapid metabolizer allele. Pharmacokinetic analyses have determined a large overlap between individuals with the ${ }^{\star} 1{ }^{\star} 1$ genotype and a single ${ }^{\star} 17$ allele. ${ }^{22}$ Others consider carriers of a single or two ${ }^{\star} 17$ alleles to be ultrarapid metabolizers. ${ }^{28}$ For the purposes of this article, we will classify homozygotes for ${ }^{\star} 1$ who carry a single ${ }^{\star} 17$ as extensive metabolizers with ${ }^{\star} 17$. Individuals with two ${ }^{\star} 17$ and no deficiency alleles are classified as ultrarapid metabolizers. There is literature demonstrating an increased risk of hemorrhagic complications for individuals who carry one or two ${ }^{\star} 17$ alleles. ${ }^{20,21}$ Only individuals homozygous for ${ }^{\star} 17$ are classified as ultrarapid metabolizers. Therefore, we must distinguish two subtypes of extensive metabolizers, those who are homozygous ${ }^{\star} 1$ and those who are compound heterozygotes for ${ }^{\star} 1$ and ${ }^{\star} 17$. The observation of an individual homozygous for the ${ }^{\star} 17$ variant and heterozygous for ${ }^{\star} 1$ and ${ }^{\star} 4$ demonstrates that in this individual the ${ }^{\star} 17$ allele is in cis with $\mathrm{a}^{\star} 4$ allele. This haplotype has been previously described in an Ashkenazi Jewish patient and was classified as $\mathrm{CYP} 2 \mathrm{C} 9{ }^{\star} 4 \mathrm{~B} .{ }^{48}$ Of note is that the patient we observed with the ${ }^{\star} 4 \mathrm{~B}$ allele is also an Ashkenazi Jew. Also of note is that the ${ }^{\star} 3$ allele was not detected in our series. This allele 
Table 3 CYP2C19 genotype frequencies from 1,396 consecutive analyses in a pan-ethnic tested population

\begin{tabular}{|c|c|c|c|c|c|}
\hline Allele 1 & Allele 2 & *17 & $\begin{array}{l}\text { Predicted } \\
\text { phenotype }\end{array}$ & Number & Frequency \\
\hline$\star 1$ & *1 & & $\begin{array}{l}\text { Extensive } \\
\text { metabolizer }\end{array}$ & 576 & $41 \%$ \\
\hline *1 & $* 1$ & *17 & $\begin{array}{l}\text { Extensive } \\
\text { metabolizer }\end{array}$ & 336 & $24 \%$ \\
\hline$\star 1$ & *2 & & $\begin{array}{l}\text { Intermediate } \\
\text { metabolizer }\end{array}$ & 277 & $20 \%$ \\
\hline *1 & *2 & *17 & $\begin{array}{l}\text { Indeterminate } \\
\text { metabolizer }\end{array}$ & 83 & $6.0 \%$ \\
\hline *1 & *1 & *17/*17 & $\begin{array}{l}\text { Ultrarapid } \\
\text { metabolizer }\end{array}$ & 53 & $3.8 \%$ \\
\hline *2 & *2 & & $\begin{array}{l}\text { Poor } \\
\text { metabolizer }\end{array}$ & 37 & $2.6 \%$ \\
\hline *1 & *3 & & $\begin{array}{l}\text { Intermediate } \\
\text { metabolizer }\end{array}$ & 13 & $0.93 \%$ \\
\hline *2 & *3 & & $\begin{array}{l}\text { Poor } \\
\text { metabolizer }\end{array}$ & 10 & $0.72 \%$ \\
\hline *1 & *4 & *17 & $\begin{array}{l}\text { Indeterminate } \\
\text { metabolizer }\end{array}$ & 4 & $0.29 \%$ \\
\hline *1 & *4 & & $\begin{array}{l}\text { Intermediate } \\
\text { metabolizer }\end{array}$ & 3 & $0.21 \%$ \\
\hline *2 & *4 & & $\begin{array}{l}\text { Poor } \\
\text { metabolizer }\end{array}$ & 2 & $0.14 \%$ \\
\hline *1 & *2 & $* 17 / * 17$ & Indeterminate & 1 & $0.07 \%$ \\
\hline *2 & *2 & *17 & Indeterminate & 1 & $0.07 \%$ \\
\hline
\end{tabular}

is the predominant allele in Asians, so it is not surprising that it was not observed in a series that excluded Asians.

Table 2 is a summary of the predicted phenotypes for the ethnic groups tested. None of the differences are statistically significant. Poor metabolizers are at the highest risk for adverse outcomes while on clopidogrel therapy; $2.8 \%$ of whites, $6.7 \%$ of African Americans, $0.87 \%$ of Hispanics, and $1.8 \%$ of Ashkenazi Jews are in this high-risk group. Ultrarapid metabolizers have the highest risk for hemorrhagic complications while on clopidogrel therapy: $4.2 \%$ of whites, $3.3 \%$ of African Americans, $2.3 \%$ of Hispanics, and $2.6 \%$ of Ashkenazi Jews are at the highest risk for hemorrhagic complications. Limiting consideration to these two highest groups means that $7 \%$ of whites, $10 \%$ of African Americans, 3.1\% of Hispanics, and $4.4 \%$ of Ashkenazi Jews will have clinically actionable results from CYP2C19 testing.

\section{Results from pan-ethnic testing}

Table 3 summarizes the data from 1,396 pan-ethnic tests submitted for analysis. Poor metabolizers account for 3.5\% of individuals, and ultrarapid metabolizers account for $3.8 \%$ of individuals, consistent with the ethnic-specific observations (see earlier).

Of note are two individuals who have an allele consisting of ${ }^{\star} 2$ in cis with ${ }^{\star} 17$; one who is homozygous for ${ }^{\star} 17$ and heterozygous for ${ }^{\star} 1{ }^{\star} 2$ and a second who is homozygous for ${ }^{\star} 2$ and heterozygous for ${ }^{\star} 17$. This allele can be classified as
CYP2C19*2B. We have found a total of three individuals carrying a ${ }^{\star} 17$ allele in cis with a deficiency allele.

\section{DISCUSSION}

The CYP2C19 genotype of an individual is only one factor in determining an individual's response to clopidogrel. Several reports have failed to find a correlation between the results of platelet reactivity testing and CYP2C19 genotype. However, results of platelet reactivity testing can vary with respect to methodology used, drug absorption, and other, as yet undefined factors. Further studies will be needed to determine whether CYP2C19 genotyping alone, platelet function testing alone, or a combination of both will lead to optimum patient care.

There was sufficient accumulated evidence regarding the correlation of CYP2C19 poor and intermediate metabolizer phenotypes with adverse outcomes for the FDA to place a "box warning" in the package insert informing clinicians of the availability of genetic testing. Subsequently, a series of publications demonstrated an increased risk for hemorrhagic complications for patients who were carriers or homozygous for the ultrarapid metabolizer allele ${ }^{\star} 17 .{ }^{20-26}$ Our data demonstrate that there are no statistically significant differences in the frequency of poor metabolizer alleles among self-described whites, Hispanics, African American and Ashkenazi Jews. However, Hispanics have a statistically significant lower frequency of the ${ }^{*} 17$ allele than either whites or African Americans.

Our data also demonstrate that the ${ }^{\star} 17$ variant can occur on $\mathrm{a}{ }^{\star} 1,{ }^{\star} 2$, or ${ }^{\star} 4$ haplotype. In patients who are heterozygous for a loss of function allele and ${ }^{\star} 1$ and also heterozygous for ${ }^{\star} 17$, it is not possible to predict their phenotype because the ${ }^{\star} 17$ allele could be in cis with either the wild type or deficiency allele. This is an important consideration when such individuals are encountered during clinical testing. For these patients, platelet function studies would be necessary to predict the phenotype.

If we only consider individuals with poor or ultrarapid phenotypes to have clinically actionable genotypes, $7.3 \%$ of tested individuals have results that could influence clinical decision making. If we expand the criteria to include ${ }^{\star} 17$ heterozygotes almost one third of patients would have clinically actionable results. Until more data are published, we cannot determine what CYP2C19 genotype results would be considered "actionable" and must leave that determination to the treating physicians.

The CYP2C19 genotype of an individual is only one factor in determining an individual's response to clopidogrel. There are conflicting data in the literature regarding the correlation of CYP2C19 genotyping data and platelet reactivity testing. A complete discussion of these data is beyond the scope of this article. ${ }^{25,27}$ Several reports have failed to find a correlation between the results of platelet reactivity testing and CYP2C19 genotype. However, results of platelet reactivity testing can vary with respect to methodology, drug absorption, and other, as yet undefined factors. Further studies will be needed to determine whether CYP2C19 genotyping alone, platelet function testing alone, or a combination of both will lead to optimum patient care. 


\section{DISCLOSURE}

The authors declare no conflict of interest.

\section{REFERENCES}

1. http://www. pharmgkb.org/search/annotatedGene/cyp2c19. Accessed 24 May 2011.

2. Mega JL, Simon T, Collet JP, et al. Reduced-function CYP2C19 genotype and risk of adverse clinical outcomes among patients treated with clopidogrel predominantly for PCI: a meta-analysis. JAMA 2010;304:1821-1830.

3. Mega JL, Close SL, Wiviott SD, et al. Cytochrome p-450 polymorphisms and response to clopidogrel. N Eng/ J Med 2009;360:354-362.

4. Simon T, Verstuyft C, Mary-Krause M, et al. Genetic determinants of response to clopidogrel and cardiovascular events. N Engl J Med 2009;360:363-375.

5. Ancrenaz $V$, Daali Y, Fontana $P$, et al. Impact of genetic polymorphisms and drug-drug interactions on clopidogrel and prasugrel response variability. Curr Drug Metab 2010;11:667-677.

6. Barker CM, Murray SS, Teirstein PS, Kandzari DE, Topol EJ, Price MJ. Pilot study of the antiplatelet effect of increased clopidogrel maintenance dosing and its relationship to CYP2C19 genotype in patients with high on-treatment reactivity. JACC Cardiovasc Interv 2010;3:1001-1007.

7. Collet JP, Hulot JS, Pena A, et al. Cytochrome P450 2C19 polymorphism in young patients treated with clopidogrel after myocardial infarction: a cohort study. Lancet 2009;373:309-317.

8. Dick RJ, Dear AE, Byron KA. Clopidogrel Resistance: Case reports of CYP2C19 gene variants in suspected coronary stent thrombosis. Heart Lung Circ 2011;20:657-658

9. Harmsze AM, van Werkum JW, Ten Berg JM, et al. CYP2C19*2 and CYP2C ${ }^{*} 3$ alleles are associated with stent thrombosis: a case-control study. Eur Heart J 2010;31:3046-3053.

10. Hwang SJ, Jeong $\mathrm{YH}$, Kim IS, et al. The cytochrome $2 \mathrm{C} 19 * 2$ and *3 alleles attenuate response to clopidogrel similarly in East Asian patients undergoing elective percutaneous coronary intervention. Thromb Res 2011:127:23-28.

11. Jeong YH, Kim IS, Park Y, et al. Carriage of cytochrome $2 \mathrm{C} 19$ polymorphism is associated with risk of high post-treatment platelet reactivity on high maintenance-dose clopidogrel of $150 \mathrm{mg} /$ day: results of the ACCEL-DOUBLE (Accelerated Platelet Inhibition by a Double Dose of Clopidogrel According to Gene Polymorphism) study. JACC Cardiovasc Interv 2010;3:731-741.

12. Jin B, Ni HC, Shen W, Li J, Shi HM, Li Y. Cytochrome P450 2C19 polymorphism is associated with poor clinical outcomes in coronary artery disease patients treated with clopidogrel. Mol Biol Rep 2011;38:1697-1702.

13. Malek LA, Przyluski J, Spiewak M, et al. Cytochrome P450 2C19 polymorphism, suboptimal reperfusion and all-cause mortality in patients with acute myocardial infarction. Cardiology 2010;117:81-87.

14. Sawada T, Shinke T, Shite J, et al. Impact of cytochrome P450 2C19*2 polymorphism on intra-stent thrombus after drug-eluting stent implantation in Japanese patients receiving clopidogrel. Circ J 2010;75:99-105.

15. Shuldiner AR, O'Connell JR, Bliden KP, et al. Association of cytochrome P450 2C19 genotype with the antiplatelet effect and clinical efficacy of clopidogrel therapy. JAMA 2009;302:849-857.

16. Sibbing $D$, Gebhard $D$, Koch $W$, et al. Isolated and interactive impact of common CYP2C19 genetic variants on the antiplatelet effect of chronic clopidogrel therapy. J Thromb Haemost 2010:8:1685-1693.

17. Trenk D, Hochholzer W, Fromm MF, et al. Cytochrome P450 2C19 681G_A polymorphism and high on-clopidogrel platelet reactivity associated with adverse 1 year clinical outcome of effective percutaneous coronary intervention with drug-eluting or bare-metal stents. J Am Col Cardiol 2008; 51:1925-1935.

18. Sofi F, Giusti B, Marcucci R, Gori AM, Abbate R, Gensini GF. Cytochrome P450 $2 C 19 * 2$ polymorphism and cardiovascular recurrences in patients taking clopidogrel: a meta-analysis. Pharmacogenomics J 2011;11:199-206.

19. Hulot JS, Collet JP, Silvain J, et al. Cardiovascular risk in clopidogrel-treated patients according to cytochrome P450 2C19*2 loss-of-function allele or proton pump inhibitor coadministration: a systematic meta-analysis. J Am Coll Cardio/ 2010:56:134-143.

20. Sibbing $D$, Koch W, Gebhard D, et al. Cytochrome $2 C 19 * 17$ allelic variant, platelet aggregation, bleeding events, and stent thrombosis in clopidogrel-treated patients with coronary stent placement. Circulation 2010;121:512-518.
21. Zabalza M, Subirana I, Lluis-Ganella C, et al. Meta-analysis of the association between cytochrome CYP2C19 loss- and gain-of-function polymorphisms and cardiovascular outcomes in patients with coronary artery disease treated with clopidogrel. Heart, in press.

22. Li-Wan-Po A, Girard T, Farndon P, Cooley C, Lithgow J. Pharmacogenetics of CYP2C19: functional and clinical implications of a new variant CYP2C 19*17. BrJ Clin Pharmacol 2010;69:222-230.

23. Kubica A, Kozinski M, Grzesk G, Fabiszak T, Navarese EP, Goch A. Genetic determinants of platelet response to clopidogrel. J Thromb Thrombolysis 2011;32:459-466

24. Campo G, Parrinello G, Ferraresi P, et al. Prospective evaluation of on-clopidogrel platelet reactivity over time in patients treated with percutaneous coronary intervention relationship with gene polymorphisms and clinical outcome. J Am Coll Cardio/ 2011;57:2474-2483.

25. Trenk D, Hochholzer W, Fromm MF, et al. Paraoxonase-1 Q192R polymorphism and antiplatelet effects of clopidogrel in patients undergoing elective coronary stent placement. Circ Cardiovasc Genet 2011:4:429-436

26. Campo G, Miccoli M, Tebaldi M, et al. Genetic determinants of on-clopidogrel high platelet reactivity. Platelets 2011;22:399-407.

27. Gurbel PA, Shuldiner AR, Bliden KP, Ryan K, Pakyz RE, Tantry US. The relation between CYP2C19 genotype and phenotype in stented patients on maintenance dual antiplatelet therapy. Am Heart J 2011;161: 598-604.

28. Justenhoven $C$, Hamann U, Pierl CB, et al. CYP2C19*17 is associated with decreased breast cancer risk. Breast Cancer Res Treat 2009;115: 391-396.

29. Paré G, Mehta SR, Yusuf S, et al. Effects of CYP2C19 genotype on outcomes of clopidogrel treatment. N Engl J Med 2010;363:1704-1714.

30. http://www.fda.gov/Drugs/DrugSafety/PostmarketDrugSafety InformationforPatientsandProviders/ucm203888.htm. Accessed 25 May 2011

31. Holmes DR Jr, Dehmer GJ, Kaul S, Leifer D, O'Gara PT, Stein CM. ACCF/ AHA clopidogrel clinical alert: approaches o the FDA "boxed warning." A report of the American College of Cardiology Foundation Task Force on Clinical Expert Consensus Documents and the American Heart Association. Circulation 2010;55:321-341.

32. Becquemont $L$, Alfirevic $A$, Amstutz $U$, et al. Practical recommendations for pharmacogenomics-based prescription: 2010 ESF-UB Conference on Pharmacogenetics and Pharmacogenomics. Pharmacogenomics 2011:12:113-124.

33. Bonello O, Armero BL, Ait Mokhtar O, et al. Clopidogrel loading dose adjustment according to platelet reactivity monitoring in patients carrying the 2C19*2 loss of function polymorphism. J Am Coll Cardiol 2010;56:1630-1636

34. Barker CM, Murray SS, Teirstein PS, Kandzari, DE, Topol EJ, Price MJ. Pilot study of antiplatelet effect of increased clopidogrel maintenance dosing and its relationship to CYP2C19 genotype in patients with high on-treatment reactivity. JACC Cardiovasc Interv 2010;3:1008-1010.

35. Santos PC, Soares RA, Santos DB, et al. CYP2C19 and ABCB1 gene polymorphisms are differently distributed according to ethnicity in the Brazilian general population. BMC Med Genet 2011;12:13.

36. Azarpira N, Namazi S, Hendijani F, Banan M, Darai M. Investigation of allele and genotype frequencies of CYP2C9, CYP2C19 and VKORC1 in Iran. Pharmacol Rep 2010;62:740-746.

37. Zand N, Tajik N, Moghaddam AS, Milanian I. Genetic polymorphisms of cytochrome P450 enzymes 2C9 and 2C19 in a healthy Iranian population. Clin Exp Pharmacol Physio/ 2007;34:102-105.

38. Man M, Farmen M, Dumaual C, et al. Genetic variation in metabolizing enzyme and transporter genes: comprehensive assessment in 3 major East Asian subpopulations with comparison to Caucasians and Africans. J Clin Pharmacol 2010;50:929-940.

39. Kudzi W, Dodoo AN, Mills JJ. Characterisation of CYP2C8, CYP2C9 and CYP2C19 polymorphisms in a Ghanaian population. BMC Med Genet 2009;10:124

40. Scott SA, Edelmann L, Kornreich R, Erazo M, Desnick RJ. CYP2C9, CYP2C19 and CYP2D6 allele frequencies in the Ashkenazi Jewish population. Pharmacogenomics 2007;8:721-730.

41. Arvanitidis K, Ragia G, lordanidou M, et al. Genetic polymorphisms of drugmetabolizing enzymes CYP2D6, CYP2C9, CYP2C19 and CYP3A5 in the Greek population. Fundam Clin Pharmacol 2007;21:419-426. 
42. Luo HR, Poland RE, Lin KM, Wan YJ. Genetic polymorphism of cytochrome P450 2C19 in Mexican Americans: a cross-ethnic comparative study. Clin Pharmacol Ther 2006;80:33-40.

43. Bravo-Villalta HV, Yamamoto K, Nakamura K, Bayá A, Okada Y, Horiuchi R. Genetic polymorphism of CYP2C9 and CYP2C19 in a Bolivian population: an investigative and comparative study. Eur J Clin Pharmacol 2005;61:179-184.

44. Luo HR, Aloumanis V, Lin KM, Gurwitz D, Wan YJ. Polymorphisms of CYP2C 19 and CYP2D6 in Israeli ethnic groups. Am J Pharmacogenomics 2004;4:395-401.

45. Pang YS, Yang YS, Wong LP, et al. Genetic polymorphism of cytochrome P450 2C19 in healthy Malaysian subjects. Br J Clin Pharmacol 2004;58: 332-335.
46. Hamdy SI, Hiratsuka M, Narahara K, et al. Allele and genotype frequencies of polymorphic cytochromes P450 (CYP2C9, CYP2C19, CYP2E1) and dihydropyrimidine dehydrogenase (DPYD) in the Egyptian population. BrJ Clin Pharmacol 2002;53:596-603.

47. Xie HG, Stein CM, Kim RB, Wilkinson GR, Flockhart DA, Wood AJ. Allelic, genotypic and phenotypic distributions of S-mephenytoin 4'hydroxylase (CYP2C19) in healthy Caucasian populations of European descent throughout the world. Pharmacogenomics 1999;9:539-549.

48. Scott SA, Martis S, Peter I, Kasai RJ, Kornreich R, Desnick RJ. Identification of CYP2C 19*4B: pharmacogenetic implications for drug metabolism including clopidogrel responsiveness. Pharmacogenomics J 2011; e-pub ahead of print 1 March 2011. 